\title{
Metabolic syndrome occurrence in university students from México City: The binomium HDL/waist circumference is the major prevalence factor
}

\author{
J. Rafael Jiménez-Flores ${ }^{1}$, Miguel Murguía-Romero ${ }^{2}$, M. Isabel Mendoza-Ramos ${ }^{1}$, \\ Santiago Sigrist-Flores ${ }^{3}$, Norma Y. Rodríguez-Soriano ${ }^{4}$, Lilia I. Ramírez-García ${ }^{1,5}$, \\ Ramiro Jesús-Sandoval ${ }^{1}, \mathrm{M}$. Araceli Álvarez-Gasca ${ }^{1}$, Esther Orozco ${ }^{6}$, \\ Rafael Villalobos-Molina ${ }^{2,5}$, A. René Méndez-Cruz ${ }^{1^{\star}}$
}

\author{
${ }^{1}$ Carrera de Médico Cirujano, FES Iztacala, UNAM, Tlalnepantla, México; ${ }^{*}$ Corresponding Author: renemen@gmail.com \\ ${ }^{2}$ Unidad de Biomedicina, FES Iztacala, UNAM, Tlalnepantla, México \\ ${ }^{3}$ Posgrado en Ciencias Biológicas, FES Iztacala, UNAM, Tlalnepantla, México \\ ${ }^{4}$ Carrera de Psicología, FES Iztacala, UNAM, Tlalnepantla, México \\ ${ }^{5}$ Carrera de Enfermería, FES Iztacala, UNAM, Tlalnepantla, México \\ ${ }^{6}$ Universidad Autónoma de la Ciudad de México, Ciudad de México, México
}

Received 12 January 2012; revised 20 February 2012; accepted 13 March 2012

\section{ABSTRACT}

Objective: Metabolic Syndrome (MetS) is the leading cause to develop type 2 diabetes worldwide. We examined associations of MetS components early in life, and their use as risk factors of acquiring MetS. Method: We used an international definition of MetS. Subjects were categorized into "Healthy"|"Not Healthy", altered parameters are low HDL-cholesterol, large waist circumference (WC), hypertriacylglycerolemia, hypertension, and hyperglycemia, in 32 combinations $\left(2^{\wedge} 5\right)$ with two values (altered/not altered). MetS was identified with three or more altered parameters. Results: A total of $\mathbf{3 4 2 4}$ students (ages 17 - 24 years) participated in the survey, and 2475 were "Not Healthy" showing at least 1 parameter altered; from them $49.6 \%$ showed low blood HDL either alone or combined, $38.2 \%$ had altered waist circumference either alone or combined; while $18.1 \%$ showed hypertriacylglycerolemia either alone or combined. Hypertension and hyperglycemia were the lowest in frequency. Conclusion: We propose that the binomium HDLI Waist Circumference is the main prevalence factor to develop MetS in the asymptomatic young population, followed by hypertriacylglycerolemia which together define MetS; while hypertension and hyperglycemia seem to occur later in MetS.

Keywords: HDL/Waist Circumference; Metabolic Syndrome; Mexican University Students

\section{INTRODUCTION}

Metabolic syndrome (MetS) has become a pandemic, it accounts for $35 \%$ of adult population (i.e., $\sim 47$ million persons) in US, whereas it is about $30 \%$ in many developing countries [1-4]. MetS is a set of metabolic impairments that includes dyslipidemia (low HDL-cholesterol and high triacylglycerols), abnormal waist circumference (overweight and obesity), high blood pressure and high fasting glucose in blood, in this study we considered metabolic alterations as those reported by Alberti et al., that define MetS, which is quite similar to the AHA definition (Table 1) [5,6]. MetS predisposes the individual to more serious complications, such as diabetes and cardiovascular diseases [7-11]. Abdominal obesity and central adiposity are involved in cardiometabolic impairment, and are commonly associated to insulin resistance and other MetS disorders [12].

The diagnostic value of MetS remains controversial: even though it provides a measurable and reliable set of criteria that help physicians to a better focused clinical data on the underlying causes, to reinforce interventions both in lifestyle changes and clinical; in contrast, those that claim that MetS is not well defined and is a poorly understood entity [9-13]. However, physicians diagnose MetS once a person has 3 or more of the cited alterations, i.e., once the person is already ill.

We hypothesized that MetS, as a multifactorial process, is a continuum between "Healthy" and "Not Healthy" status, thus, it is possible to elucidate early events of that process that might predict progression to future chronic disease. In support of this contention, a recent paper 
Table 1. Reference values of clinical and anthropometric parameters, according to Alberti et al. metabolic syndrome definition [5].

\begin{tabular}{cc}
\hline Parameter & Categorical cut-off point \\
\hline HDL Cholesterol & $<50 \mathrm{mg} / \mathrm{dL}$ in women \\
& $<40 \mathrm{mg} / \mathrm{dL}$ in men \\
Waist circumference & $\geq 80 \mathrm{~cm} \mathrm{in} \mathrm{women;}$ \\
& $\geq 90 \mathrm{~cm} \mathrm{in} \mathrm{men}$ \\
Triglycerides & $\geq 150 \mathrm{mg} / \mathrm{dL}$ \\
Blood pressure & $\geq 130 \mathrm{~mm} \mathrm{Hg}$ systolic; \\
Fasting glucose & $\geq 85 \mathrm{~mm} \mathrm{Hg}$ diastolic \\
\hline
\end{tabular}

suggests that physicians should treat individual risk factors, instead than MetS [14]. We aimed to determine risk factors in previous stages of MetS, and their use as predictors in the population.

\section{METHODS}

\subsection{Participants}

The study sample, 3424 first year university alumni, was representative of Mexican university students, aged 17 to 24 years, of the metropolitan area. Data were obtained by the Multidisciplinary Group to Investigate Health and Academic Performance (GMISARA), from Facultad de Estudios Superiores Iztacala, Universidad Nacional Autónoma de México (U.N.A.M.). GMISARA surveys a complex, multistage, and geographic area design for collecting data from public universities of México City metropolitan area (U.N.A.M. and Universidad Autónoma de la Ciudad de México, U.A.C.M.); all students signed an informed consent, the protocol was approved by the ethical committee of Facultad de Estudios Superiores Iztacala.

Before the study, none of the students perceived themselves as ill, and no metabolic disorder was diagnosed by a physician. Data of the study sample were collected over a 3-year survey (2008-2010). GMISARA uses trained personnel to conduct interviews for collecting reliable data that include demographic, socioeconomic, dietary, and health related information. Medical personnel obtained medical and physiological measurements, and CARPERMOR, S.A., an internationally certified laboratory, obtained laboratory data.

\subsection{Data for Diagnosing of Metabolic Disorders}

Students were required to come to the university, either U.N.A.M. or U.A.C.M., between 7 - 10 AM after fasting for at least 9 hours. Waist circumference was measured to the nearest $0.1 \mathrm{~cm}$ at minimal respiration at the end of normal expiration, with a flexible measuring tape placed at the high point of the iliac crest, when the student was in a standing position. Diastolic and systolic blood pressure (BP) values were obtained after replicated measurements. After resting quietly in a sitting position for 5 minutes and determination of the maximum inflation level, up to 4 consecutive BP readings were obtained with a standard aneroid sphygmomanometer (Model DS44, WelchAllyn). The maximum values of replicate systolic and diastolic measurements provided estimates of current BP values. Glucose, triacylglycerols and HDL concentration were determined by standard methods (CARPERMOR, S.A. de C.V.).

\subsection{Metabolic Disorder and MetS Characterization}

In this work, students were classified as having metabolic disorders (i.e., "Not Healthy") if they had altered values in any one of the five parameters: HDL-cholesterol, waist circumference, triacylglycerols, blood pressure, and glucose (Table 1), or "Healthy" if they showed none of them. According to Alberti et al. definition, MetS was diagnosed if tree or more of those parameters were altered $[5,6]$.

\section{RESULTS}

\subsection{Prevalence of MetS and Individual Risk Factors}

There were 3424 first year university students in the sample, where $68.4 \%$ were women and $31.7 \%$ men (Table 2). There were between $1.6 \%$ (24 years-old) to $33.2 \%$ (18 years-old) in each age group (range 17 - 24 yearsold), with an average of 19 years-old.

An estimated $14.4 \%$ of students in the survey had MetS (494/3424, Table 2). Overall, the observed frequency order was low HDL $>\mathrm{WC}>$ higher triacylglycerols $>$ hypertension $>$ hyperglycemia (Table 2).

\subsection{Prevalence of Risk Factor Combinations}

Table 3 shows the 32 combinations $\left(2^{\wedge} 5\right)$ of five parameters with two possible values (altered/not altered), with prevalence estimates for the diagnostic components of MetS. The case with none altered parameter ("Healthy") had a frequency of $27.7 \%(949 / 3424)$; while the remaining $72.3 \%$ are those cases with one to five altered parameters. Table 3 also shows the frequencies of "Not Healthy" students, i.e., taking 2475 cases as $100 \%$. The cases are sorted by frequency in descending order. Notice that cases 2, 3 and 4, represent $57 \%$ of all "Not Healthy" students, and involve HDL-cholesterol or Waist Circumference, or both. Thus, the binomium HDL/Waist Circumference is likely to be the main association that could 
Table 2. General data and prevalence of metabolic alterations and MetS in the studied population.

\begin{tabular}{lcc}
\hline \multicolumn{1}{c}{ Total students } & 3424 & \\
\hline Age (years) & $17-24$ & \\
Women & 2341 & \\
Men & 1083 & \\
Students with MetS & $494(14.4 \%)$ & \\
Students without MetS & 2930 & $1725(50.4 \%)$ \\
\hline \multicolumn{1}{c}{ MetS parameters } & altered & not altered \\
\hline HDL cholesterol & $1699(49.6 \%)$ & $1987(58.0 \%)$ \\
Waist circumference & $1437(42.0 \%)$ & $2798(81.7 \%)$ \\
Triglycerides & $625(18.3 \%)$ & $3010(87.9 \%)$ \\
Blood pressure & $414(12.1 \%)$ & $3162(92.3 \%)$ \\
Glucose & $262(7.7 \%)$ &
\end{tabular}

cause MetS. Eleven cases (cases 2 to 12 ) rise to $\approx 86 \%$ and none showed altered glycemia, which suggests that dysglycemia is not a main cause of MetS.

\section{DISCUSSION}

We name pre-MetS stage to any stage included in the "Not Healthy" condition, with one or two altered parameters. It is relevant to study pre-MetS stages, since they might be critical points to prevent developing MetS in the population. We measured the frequency of each combination of altered metabolic parameters, and assigned more strength to combinations with higher values among the cases, with the same number of altered parameters. Then, by observing the frequency of cases with one altered parameter, we propose that the parameter with the highest frequency is the main starting cause of MetS.

That assumption is supported by the fact that the studied sample is an apparent healthy population. According with this reasoning, low HDL cholesterol, is a likely starting point of the MetS process, since its prevalence among students was the highest $(24.12 \%)$, followed by the increase of WC (13.54\%). Then the binomium HDL/ Waist Circumference increased the frequency to $57 \%$, which strongly suggest it is the main cause of the MetS.

In contrast, the other three parameters (TRI, BP and GLU) had lower frequencies, thus they do not seem important starting points of MetS process. Our contention is supported by the fact that the only combination not represented in the sample is [TRI, BP, GLU, case 32 from Table 3]. In addition, eleven cases (cases 2 to 12) rise to $\approx 86 \%$ and none showed altered glycemia, which sug- gests that dysglycemia is not a main cause of MetS.

It is known that the sequential events leading to MetS are associated with the development of obesity and/or insulin resistance first, then the appearance of other metabolic disturbances until they evolve to diseases that threaten life $[12,15,16]$. We found that about $32 \%$ of "Not Healthy" students were not obese (cases 2, 6, 14, 18, 22, 24, 30, and 31 in Table 3), and showed low HDL.

Our data prompted us to hypothesize: MetS, as a multifactorial process, is a continuum between a "Healthy" and a "Not Healthy" status; then by elucidating early stages of a "Not Healthy" condition, we may predict the development of MetS. Moreover, we suggest that the binomium HDL/WC is the main prevalence factor and the main predictor of MetS occurrence, since low HDL in blood is very frequent in the population, as described for Hispanic and White adolescents [12] and older Mexicans [17]. In addition, an ABCA1 genetic variation (R230C variant) which seems exclusive to native American ancestry populations, has been associated with low HDL levels, and other metabolic traits in adults, as well as in Mexican children [18]. It would be interesting to determine the R230C gene variant in the White adolescents [12], and define its possible association with low HDL in them. Then our hypothesis could be represented as in Figure 1 (a synthesis of data in Table 3), which shows both a structural association between alterations in the five parameters analyzed, and the relationships more probable or frequent of evolution to MetS.

In Figure 1, the size of the circle and the thickness of each line connecting them represent the hierarchical association by pairs of parameters. Thus, early detection of low HDL in blood along with WC measurement could be a marker for MetS development, suggesting that more

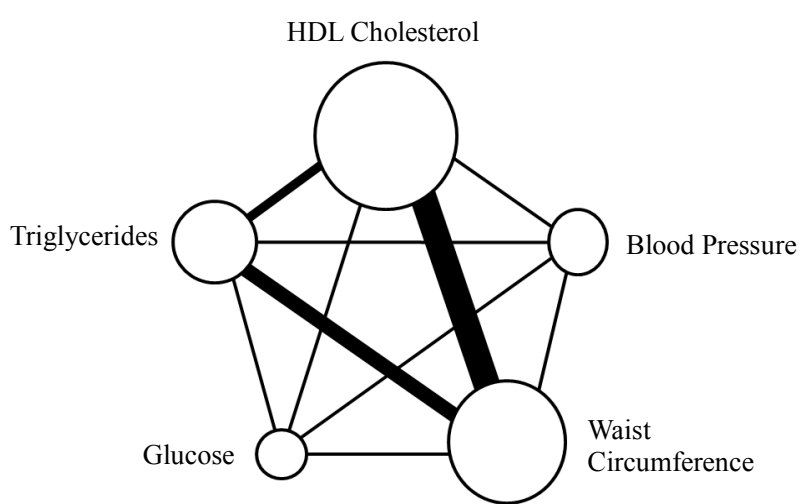

Figure 1. Schematic representation of MetS parameters and their relationship. The diameter of each circle is proportional to the percentage of students with an altered value; the thickness of each line is proportional to the suggested strength in the relationship between parameters that the line is connecting, according to percentage of students with altered values (Table 3). 
Table 3. Frequency by case. Each case represents a combination of the five MetS parameters with two possible values: $y=$ altered; $n$ $=$ not altered. $(\mathrm{n}=3424) . \mathrm{HDL}=\mathrm{HDL}$ cholesterol, $\mathrm{WC}=$ waist circumference, $\mathrm{TRI}=$ triacylglycerols, $\mathrm{BP}=$ blood pressure, $\mathrm{GLU}=$ glucose.

\begin{tabular}{|c|c|c|c|c|c|c|c|c|c|}
\hline & \multicolumn{5}{|c|}{ Metabolic syndrome parameter } & \multirow{2}{*}{$\begin{array}{l}\text { No. of altered } \\
\text { parameters }\end{array}$} & \multirow{2}{*}{$\begin{array}{l}\text { Students } \\
(\mathrm{n}=3424)\end{array}$} & \multirow{2}{*}{$\%$ Not healthy } & \multirow{2}{*}{$\begin{array}{l}\text { Accumulated \% } \\
\text { Not healthy } \\
(\mathrm{n}=2475)\end{array}$} \\
\hline & HDL & $\mathrm{WC}$ & TRI & $\mathrm{BP}$ & GLU & & & & \\
\hline Case 1 (Healthy) & $\mathrm{n}$ & $\mathrm{n}$ & $\mathrm{n}$ & $\mathrm{n}$ & $\mathrm{n}$ & 0 & 949 & & \\
\hline Case 2 & $\mathrm{y}$ & $\mathrm{n}$ & $\mathrm{n}$ & $\mathrm{n}$ & $\mathrm{n}$ & 1 & 597 & $24.12 \%$ & $24.12 \%$ \\
\hline Case 3 & $\mathrm{y}$ & $\mathrm{y}$ & $\mathrm{n}$ & $\mathrm{n}$ & $\mathrm{n}$ & 2 & 486 & $19.64 \%$ & $43.76 \%$ \\
\hline Case 4 & $\mathrm{n}$ & $\mathrm{y}$ & $\mathrm{n}$ & $\mathrm{n}$ & $\mathrm{n}$ & 1 & 335 & $13.54 \%$ & $57.29 \%$ \\
\hline Case 5 & $\mathrm{y}$ & $\mathrm{y}$ & $\mathrm{y}$ & $\mathrm{n}$ & $\mathrm{n}$ & 3 & 209 & $8.44 \%$ & $65.74 \%$ \\
\hline Case 6 & $\mathrm{y}$ & $\mathrm{n}$ & $\mathrm{y}$ & $\mathrm{n}$ & $\mathrm{n}$ & 2 & 106 & $4.28 \%$ & $70.02 \%$ \\
\hline Case 7 & $\mathrm{n}$ & $\mathrm{n}$ & $\mathrm{n}$ & $\mathrm{y}$ & $\mathrm{n}$ & 1 & 94 & $3.80 \%$ & $73.82 \%$ \\
\hline Case 8 & $\mathrm{n}$ & $\mathrm{n}$ & $\mathrm{y}$ & $\mathrm{n}$ & $\mathrm{n}$ & 1 & 71 & $2.87 \%$ & $76.69 \%$ \\
\hline Case 9 & $\mathrm{y}$ & y & $\mathrm{n}$ & $\mathrm{y}$ & $\mathrm{n}$ & 3 & 65 & $2.63 \%$ & $79.31 \%$ \\
\hline Case 10 & $\mathrm{n}$ & $\mathrm{y}$ & $\mathrm{y}$ & $\mathrm{n}$ & $\mathrm{n}$ & 2 & 62 & $2.51 \%$ & $81.82 \%$ \\
\hline Case 11 & $\mathrm{n}$ & $\mathrm{y}$ & $\mathrm{n}$ & $\mathrm{y}$ & $\mathrm{n}$ & 2 & 55 & $2.22 \%$ & $84.04 \%$ \\
\hline Case 12 & $\mathrm{y}$ & $\mathrm{y}$ & $\mathrm{y}$ & $\mathrm{y}$ & $\mathrm{n}$ & 4 & 51 & $2.06 \%$ & $86.10 \%$ \\
\hline Case 13 & $\mathrm{n}$ & $\mathrm{n}$ & $\mathrm{n}$ & $\mathrm{n}$ & $\mathrm{y}$ & 1 & 44 & $1.78 \%$ & $87.88 \%$ \\
\hline Case 14 & $\mathrm{y}$ & $\mathrm{n}$ & $\mathrm{n}$ & $\mathrm{y}$ & $\mathrm{n}$ & 2 & 42 & $1.70 \%$ & $89.58 \%$ \\
\hline Case 15 & $\mathrm{y}$ & $\mathrm{y}$ & $\mathrm{n}$ & $\mathrm{n}$ & $\mathrm{y}$ & 3 & 35 & $1.41 \%$ & $90.99 \%$ \\
\hline Case 16 & $\mathrm{n}$ & $\mathrm{y}$ & $\mathrm{n}$ & $\mathrm{n}$ & $\mathrm{y}$ & 2 & 34 & $1.37 \%$ & $92.36 \%$ \\
\hline Case 17 & $\mathrm{y}$ & $\mathrm{y}$ & $\mathrm{y}$ & $\mathrm{n}$ & $\mathrm{y}$ & 4 & 30 & $1.21 \%$ & $93.58 \%$ \\
\hline Case 18 & $\mathrm{y}$ & $\mathrm{n}$ & $\mathrm{n}$ & $\mathrm{n}$ & $\mathrm{y}$ & 2 & 21 & $0.85 \%$ & $94.42 \%$ \\
\hline Case 19 & $\mathrm{n}$ & $\mathrm{y}$ & $\mathrm{y}$ & $\mathrm{y}$ & $\mathrm{n}$ & 3 & 18 & $0.73 \%$ & $95.15 \%$ \\
\hline Case 20 & $\mathrm{y}$ & $\mathrm{y}$ & $\mathrm{y}$ & $\mathrm{y}$ & $\mathrm{y}$ & 5 & 17 & $0.69 \%$ & $95.84 \%$ \\
\hline Case 21 & $\mathrm{n}$ & $\mathrm{n}$ & $\mathrm{n}$ & $\mathrm{y}$ & $\mathrm{y}$ & 2 & 16 & $0.65 \%$ & $96.48 \%$ \\
\hline Case 22 & $\mathrm{y}$ & $\mathrm{n}$ & $\mathrm{y}$ & $\mathrm{y}$ & $\mathrm{n}$ & 3 & 14 & $0.57 \%$ & $97.05 \%$ \\
\hline Case 23 & $\mathrm{n}$ & $\mathrm{y}$ & $\mathrm{n}$ & $\mathrm{y}$ & $\mathrm{y}$ & 3 & 13 & $0.53 \%$ & $97.58 \%$ \\
\hline Case 24 & $\mathrm{y}$ & $\mathrm{n}$ & $\mathrm{y}$ & $\mathrm{n}$ & $\mathrm{y}$ & 3 & 12 & $0.48 \%$ & $98.06 \%$ \\
\hline Case 25 & $\mathrm{y}$ & $\mathrm{y}$ & $\mathrm{n}$ & $\mathrm{y}$ & $\mathrm{y}$ & 4 & 11 & $0.44 \%$ & $98.51 \%$ \\
\hline Case 26 & $\mathrm{n}$ & $\mathrm{n}$ & $\mathrm{y}$ & $\mathrm{n}$ & $\mathrm{y}$ & 2 & 10 & $0.40 \%$ & $98.91 \%$ \\
\hline Case 27 & $\mathrm{n}$ & $\mathrm{y}$ & $\mathrm{y}$ & $\mathrm{n}$ & $\mathrm{y}$ & 3 & 9 & $0.36 \%$ & $99.27 \%$ \\
\hline Case 28 & $\mathrm{n}$ & $\mathrm{n}$ & $\mathrm{y}$ & $\mathrm{y}$ & $\mathrm{n}$ & 2 & 8 & $0.32 \%$ & $99.60 \%$ \\
\hline Case 29 & $\mathrm{n}$ & $\mathrm{y}$ & $\mathrm{y}$ & $\mathrm{y}$ & $\mathrm{y}$ & 4 & 7 & $0.28 \%$ & $99.88 \%$ \\
\hline Case 30 & $\mathrm{y}$ & $\mathrm{n}$ & $\mathrm{n}$ & $\mathrm{y}$ & $\mathrm{y}$ & 3 & 2 & $0.08 \%$ & $99.96 \%$ \\
\hline Case 31 & $\mathrm{y}$ & $\mathrm{n}$ & $\mathrm{y}$ & $\mathrm{y}$ & $\mathrm{y}$ & 4 & 1 & $0.04 \%$ & $100.00 \%$ \\
\hline Case 32 & $\mathrm{n}$ & $\mathrm{n}$ & $\mathrm{y}$ & $\mathrm{y}$ & $\mathrm{y}$ & 3 & 0 & $0.00 \%$ & $100.00 \%$ \\
\hline
\end{tabular}


focused intervention efforts are needed to avoid the syndrome, i.e., lifestyle changes like fish, vegetables and fruits consumption, physical activity, and if needed clinical interventions [19-22]. Although no longitudinal study was conducted, the case analysis, according to number and kind of altered parameters, allowed us to elucidate plausible hypothesis on how risk factors evolve to MetS in young population. The early identification of metabolic alterations in young students, allowed GMISARA physicians to propose them alternatives to prevent or postpone developing MetS.

In order to improve the physical health of students, we built a knowledge-based system for the diagnosis of MetS and metabolic disorders, and the recommendation from the physician to the student diagnosed with one or more of them [23].

As a way to make an impact on students' life style, we built an Internet tool that allows students to know their health regarding MetS: the Metabolodrome (http://campus.iztacala.unam.mx/mmrg/sm/).

In conclusion, we propose that the binomium HDL/ Waist Circumference is the main prevalence factor and could be a good predictor to develop MetS in the asymptomatic young population, followed by hypertriacylglycerolemia which together define MetS; while hypertension and hyperglycemia seem to occur later in MetS.

\section{ACKNOWLEDGEMENTS}

Supported in part by grants PAPIIT IN226708, PAPIME PE204707, PAPIME PE303507, PAPCA 2008-2009, F.E.S. Iztacala (S. CházaroOlvera), from U.N.A.M.; PICDS08-69 from ICyT-GDF. Authors are indebted to CARPERMOR, S.A. de C.V., U.A.C.M., S.N.I., Lucina Pérez-Bautista, Julia Reyes-Reali, Jorge A. Herrera-Rueda, R. Daniel González-Quintero, Estrella González-Dalhaus, Jorge L. Cruz-López, Miguel Ángel Romero, Carlos Díaz-Ceja, M. Refugio Ríos-Saldaña, M. de los Ángeles Gutiérrez, Zoe Palafox, Diana Sedano, Ricardo Galicia, Ignacio Tepale.

\section{REFERENCES}

[1] Ford, E.S., Giles, W.H. and Dietz, W.H. (2002) Prevalence of the metabolic syndrome among US adults. Findings from the Third National Health and Nutrition Examination Survey. The Journal of the American Medical Association, 287, 356-359. doi:10.1001/jama.287.3.356

[2] Misra, A. and Khurana, L. (2008) Obesity and the metabolic syndrome in developing countries. Journal of Clinical Endocrinology and Metabolism, 93, S9-S30. doi: $10.1210 /$ jc. $2008-1595$

[3] Ginsberg, H.R. and MacCallum, P.R. (2009) The obesity, metabolic syndrome, and type 2 diabetes mellitus pandemic: Part I. Increased cardiovascular disease risk and the importance of atherogenic dyslipidemia in persons with the metabolic syndrome and type 2 diabetes mellitus. Journal of the CardioMetabolic Syndrome, 4, 113-119. doi:10.1111/j.1559-4572.2008.00044.x

[4] Cornier, M.A., Dabelea, D. and Hernandez, T. (2008) The metabolic syndrome. Endocrine Reviews, 29, 777-882. doi:10.1210/er.2008-0024

[5] Alberti, K.G., Eckel, R.H., Grundy, S.M., Zimmet, P.Z., Cleeman, J.I., Donato, K.A., Fruchart, J.C., James, W.P., Loria, C.M. and Smith, S.C. Jr. (2009) Harmonizing the metabolic syndrome. A Joint Interim Statement of the International Diabetes Federation Task Force on Epidemiology and Prevention; National Heart, Lung, and Blood Institute; American Heart Association; World Heart Federation; International Atherosclerosis Society; and International Association for the Study of Obesity. Circulation 120, 1640-1645.

doi:10.1161/CIRCULATIONAHA.109.192644

[6] Grundy, S.M., Cleeman, J.I., Daniels, S.R., Donato, K.A., Eckel, R.H., Franklin, B.A., Gordon, D.J., Krauss, R.M., Savage, P.J., Smith, S.C. Jr., Spertus, J.A. and Costa, F. (2005) Diagnosis and management of the metabolic syndrome. An American Heart Association/National Heart, Lung, and Blood Institute Scientific Statement. Circulation, 112, 2735-2752. doi:10.1161/CIRCULATIONAHA.105.169404

[7] Cho, L.W. (2011) Metabolic syndrome. Singapore Medical Journal, 52, 779-785.

[8] Ghosh, A. (2011) The metabolic syndrome: A definition dilemma. Cardiovascular Journal of Africa, 22, 295-296.

[9] Reaven, G.M. (2005) The metabolic syndrome: Requiescat-in-pace. Clinical Chemistry, 5, 931-938. doi:10.1373/clinchem.2005.048611

[10] Simmons, R.K., Alberti, K.G.M.M., Gale, E.A.M., Colagiuri, S., Tuomiletho, J., Qiao, Q., Ramachandran, A., Tajima, N., Brajkovich Mirchov, I., Ben-Nakhi, A., Reaven, G., Hama Sambo, B., Mendis, S. and Roglic, G. (2011) The metabolic syndrome: useful concept or clinical tool? Report of a WHO expert consultation. Diabetologia, 53, 600-605. doi:10.1007/s00125-009-1620-4

[11] Reaven, G.M. (2011) The metabolic syndrome: Time to get off the merry-go-round? Journal of Internal Medicine, 269, 127-136. doi:10.1111/j.1365-2796.2010.02325.x

[12] Johnson, W., Kroon, J. and Greenway, F. (2009) Prevalence of risk factors for metabolic syndrome in adolescents. National health and nutrition examination survey (NHANES), 2001-2006. Archives of Pediatric and Adolescent Medicine, 163, 371- 377. doi:10.1001/archpediatrics.2009.3

[13] Kahn, R., Buse, J., Ferrannini, E. and Stern, M. (2005) The metabolic syndrome: Time for a critical appraisal. Joint statement from the American Diabetes Association and the European Association for the Study of Diabetes. Diabetologia, 48, 1684-1699. doi:10.1007/s00125-005-1876-2

[14] Mente, A., Yusuf, S., Islam, S., McQueen, M.J., Tanomsup, S., Onen, C.L., Rangarajan, S., Gerstein, H.C. and Anand, S.S. (2010) INTERHEART investigators, metabolic syndrome and risk of acute myocardial infarction a 
case-control study of 26,903 Subjects from 52 countries. Journal of American College of Cardiology, 55, 23902398. doi:10.1016/j.jacc.2009.12.053

[15] Brandão, A.P., Brandão, A.A., de Magalhães, M.E. and Pozzan, R. (2008) Management of metabolic syndrome in young population. American Journal of Therapeutics, 15, 356-361. doi:10.1097/MJT.0b013e318164c107

[16] Cook, S., Weitzman, M. and Auinger, P. (2003) Prevalence of a metabolic syndrome phenotype in adolescents. Findings from the Third National Health and Nutrition Examination Survey, 1988-1994. Archives of Pediatric and Adolescent Medicine, 157, 821-827. doi:10.1001/archpedi.157.8.821

[17] Aguilar-Salinas, C.A., Olaiz, G. and Valles, V. (2001) High prevalence of low HDL cholesterol concentrations and mixed hyperlipidemia in a Mexican nationwide survey. Journal of Lipid Research, 42, 1298-1307.

[18] Flores-Dorantes, T., Arellano-Campos, O., Posadas-Sánchez, R., Villarreal-Molina, T., Medina-Urrutia, A., RomeroHidalgo, S., Yescas-Gómez, P., Pérez-Méndez, O., JorgeGalarza, E., Tusié-Luna, T., Villalobos-Comparán, L., Jacorbo-Albavera, L., Villamil-Ramírez, H., López-Contreras, B.E., Aguilar-Salinas, C.A., Posadas-Romero, C. and Canizales-Quinteros, S. (2010) Association of R230C ABCA1 gene variant with low HDL-C levels and abnormal HDL subclass distribution in Mexican school-aged children. Clinica Chimica Acta, 411, 1214-1217. doi:10.1016/j.cca.2010.04.025

[19] Al-Gayyar, M.M., Shams, M.E. and Barakat, E.A. (2012)
Fish oil improves lipid metabolism and ameliorates inflammation in patients with metabolic syndrome: Impact of nonalcoholic fatty liver disease. Pharmaceutical Biology, 50, 297-303. doi:10.3109/13880209.2011.604088

[20] Perez-Martinez, P., Garcia-Rios, A., Delgado-Lista, J., Perez-Jimenez, F. and Lopez-Miranda, J. (2011) Metabolic syndrome: Evidences for a personalized nutrition. Molecular Nutrition \& Food Research, 56, 67-76. doi:10.1002/mnfr.201100531

[21] Guevara-Cruz, M., Tovar, A.R., Aguilar-Salinas, C.A., Medina-Vera, I., Gil-Zenteno, L., Hernández-Viveros, I., López-Romero, P., Ordaz-Nava, G., Canizales-Quinteros, S., Guillen Pineda, L.E. and Torres, N. (2012) A dietary pattern including nopal, chia seed, soy protein, and oat reduces serum triglycerides and glucose intolerance in patients with metabolic syndrome. Journal of Nutrition, 142, 64-69. doi:10.3945/jn.111.147447

[22] Das, M., Pal, S. and Ghosh, A. (2011) Prevalence of the metabolic syndrome in people of Asian Indian origin: Outcomes by definitions. Cardiovascular Journal of Africa, 22, 303-305. doi:10.5830/CVJA-2010-070

[23] Murguía-Romero, M., Méndez-Cruz, R., Villalobos-Molina, R., Rodríguez-Soriano, N.Y., González-Dalhaus, E. and Jiménez-Flores, R. (2010) Knowledge-based system for diagnosis of metabolic alterations in undergraduate students. In: Hernández-Aguirre, A. and Reyes-Garcia, C.A. Eds., Advances in Artificial Intelligence. MICAI Part I. Lecture Notes on Artificial Intelligence 6437, SpringerVerlag, Berlin/Heidelberg, 467-476. 